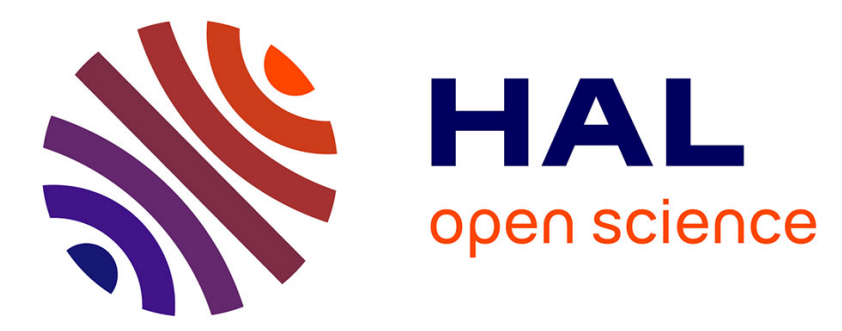

\title{
Spent nuclear fuel/water interface behavior: Alpha dose rate profile determination for model surfaces and microcracks by using Monte-Carlo methods
}

\author{
M. Tribet, Sarah Mougnaud, C. Jegou
}

\section{- To cite this version:}

M. Tribet, Sarah Mougnaud, C. Jegou. Spent nuclear fuel/water interface behavior: Alpha dose rate profile determination for model surfaces and microcracks by using Monte-Carlo methods. Journal of Nuclear Materials, 2017, 488, pp.245-251. 10.1016/j.jnucmat.2017.03.027 • cea-02421897

HAL Id: cea-02421897 https://hal-cea.archives-ouvertes.fr/cea-02421897

Submitted on 19 Feb 2020

HAL is a multi-disciplinary open access archive for the deposit and dissemination of scientific research documents, whether they are published or not. The documents may come from teaching and research institutions in France or abroad, or from public or private research centers.
L'archive ouverte pluridisciplinaire HAL, est destinée au dépôt et à la diffusion de documents scientifiques de niveau recherche, publiés ou non, émanant des établissements d'enseignement et de recherche français ou étrangers, des laboratoires publics ou privés. 


\title{
Spent nuclear fuel / water interface behavior: alpha dose rate profile determination for model surfaces and microcracks by using Monte-Carlo methods
}

\author{
M. Tribet*, S. Mougnaud, C. Jégou \\ CEA, DEN, DE2D, SEVT, F-30207 Bagnols-sur-Cèze, France
}

* Corresponding author. Tel.: +33 466339152.

Email address: magaly.tribet@cea.fr

Keywords: alpha irradiation, dose rate, Monte Carlo simulations, spent fuel, uranium dioxide, cracks, alpha radiolysis, long term behavior.

\section{Abstract}

This work aims to better understand the nature and evolution of energy deposits at the $\mathrm{UO}_{2} /$ water reactional interface subjected to alpha irradiation, through an original approach based on Monte-Carlo-type simulations, using the MCNPX code. Such an approach has the advantage of describing the energy deposit profiles on both sides of the interface $\left(\mathrm{UO}_{2}\right.$ and water). The calculations have been performed on simple geometries, with data from an irradiated UOX fuel (burnup of $47 \mathrm{GWd} . \mathrm{t}_{\mathrm{HM}}{ }^{-1}$ and 15 years of alpha decay). The influence of geometric parameters such as the diameter and the calculation steps at the reactional interface are discussed, and the exponential laws to be used in practice are suggested. The case of cracks with various different apertures (from 5 to $35 \mu \mathrm{m}$ ) has also been examined and these calculations have also enabled new information on the mean range of radiolytic species in cracks, and thus on the local chemistry. 


\section{Introduction}

For many years, studies to better understand the alteration process at the $\mathrm{UO}_{2} /$ water interface under alpha irradiation have been carried out internationally in order to be able to predict the long-term behavior of spent fuel in deep geological repositories [1-11]. The alpha irradiation from the actinides present in the fuel will dominate over the long term, and may thus lead to an oxidizing dissolution of the $\mathrm{UO}_{2}$ matrix by the production of oxidizing species through alpha radiolysis of water. Alpha particles, whose energy is about $5 \mathrm{MeV}$, typically have a high linear energy transfer value (LET) and relatively short paths (a few microns) within the media they pass through, which can induce considerable fluctuations in local chemistry. Determining the energy deposits between the solid and the solution is therefore essential in order to better understand the physical and chemical evolution of the $\mathrm{UO}_{2} /$ water reactional interface. Several works have sought to describe the energy deposit profile in water at the reactional interface by using analytical approaches which integrate the geometry of the system studied [12-13]. These have given decreasing exponential functions with a maximum energy deposit at the extreme surface of the fuel. The present work detailed here implemented another calculation approach, based on Monte Carlo-type simulations carried out using the MCNPX code, firstly for comparisons but also in order to add to and complete existing results. Thus the energy deposit profiles were calculated both in the water and in the $\mathrm{UO}_{2}$ solid, which had never been done previously. Different geometries were taken into account, i.e. spheres, pellets, and different sizes of cracks, typical of those found in a fuel irradiated in a reactor. The complete set of results is given here, and first discussed as concerns the geometry and the calculation hypotheses ("refinement steps"). Then the general equations able to fit the profiles are proposed, and the consequences on the physics and the chemistry of the system are described. 


\section{Method and calculations}

\subsection{The MCNPX simulation code}

To simulate the passage of alpha particles through the fuel from which they are emitted into water, the MCNPX calculation code [14] was selected because of its ergonomics in designing materials, geometrical shapes and radioactive sources as well as its ability to handle scales from centimeter to micron, necessary when focusing on alpha ranges.

MCNPX is an extension of MCNP (for Monte Carlo N-Particle Transport Code), a particle transport code based on the Boltzmann transport equation solver by the repeated random sampling Monte Carlo method [15]. Each particle has its own "history" and is followed from its emission to its disappearance. When the particle passes through matter, it leads to a large number of events (interactions) which are taken into account using physics equations and cross-sections representing the interaction probabilities, available in libraries. The results are obtained by tallying events (e.g. number of particles crossing a surface, or number of particles that have undergone a collision in a finite volume of the geometry...) and they are statistical. Thus the code gives results averaged over the events with the statistical error 
(standard deviation) [16]. In this study, an alpha particle was no longer considered once its energy decreased below a $1 \mathrm{keV}$ cut-off energy.

\subsection{Description of the modeled systems}

First, the characteristics of the modeled spent fuel are described, followed by the three kinds of spent fuel/water interfaces of increasing complexity which were simulated.

\subsubsection{Spent fuel features}

This study chose to consider the features of a "fresh" spent fuel with a burnup of 47 GWd.t $\mathrm{H}_{\mathrm{HM}}{ }^{-1}$. The fuel was initially enriched to $3.1 \mathrm{wt} \%{ }^{235} \mathrm{U}$ and then irradiated in the French Fessenheim reactor for four cycles. The most important radionuclides contributing to alpha activity are detailed in [12]. They lead to an alpha activity of $4.73 \times 10^{8} \mathrm{~Bq} \cdot \mathrm{g}_{\mathrm{HM}}{ }^{-1}$ after 15 years of alpha decay. The average value of emitted alpha particles is $5.3 \mathrm{MeV}$. The simplified chemical composition considered in the calculations is ${ }^{238} \mathrm{UO}_{2}$, with a mass density of $10.8 \mathrm{~g} \cdot \mathrm{cm}^{-3}$.

\subsubsection{Spherical and cylindrical geometries}

Two different geometries were considered to describe the $\mathrm{UO}_{2}$ fuel/water interface. First, to give a very simple approach to the spent fuel/water interface, a spherical spent fuel "fragment" was considered as a homogeneous material within which alpha particle emission was isotropic and homogeneous, and which was surrounded by water. Second, in order to 
be more representative of the real $\mathrm{UO}_{2}$ fuel shape, cylindrical spent fuel pellets were designed.

To calculate the deposited energy as a function of the distance from the interface in each case, the system was virtually divided into several thin layers (also called "steps") on each side of the interface (i.e. the spent fuel and the water parts) over a distance corresponding to the alpha range in the material concerned, i.e. the last $12.6 \mu \mathrm{m}$ in $\mathrm{UO}_{2}$ fuel and the first $40 \mu \mathrm{m}$ in water, as determined using the SRIM software [17]. Each layer's thickness was adapted to the accuracy necessary, up to $0.0625 \mu \mathrm{m}$ very near the interface. The distance is referred to from the fuel/water interface: it is therefore negative for layers within the fuel and positive for layers within the water. A schematic layout of the two kinds of modeled systems is presented in Figure 1. The main parameters taken into account in the MCNP calculations are given in Table 1.

Concerning the spherical geometry, $\mathrm{UO}_{2}$ fuel fragment diameters ranging from $100 \mu \mathrm{m}$ to $1 \mathrm{~mm}$ were considered in order to better understand possible changes in the energy deposition profiles. To better focus on the fuel/water interface of the flat part of the cylindrical geometry, $1 \mathrm{~mm}$ thick pellets were considered, and two diameters $(8 \mathrm{~mm}$ and $2 \mathrm{~cm})$ were studied in order to assess a possible edge effect on the interface description.

\subsubsection{Cracks}

During its residence time in the reactor, the temperature gradient between the center of the $\mathrm{UO}_{2}$ fuel pellet and the periphery led to ceramic fracturing. This induced the formation of cracks with apertures ranging from 5 to $35 \mu \mathrm{m}$ [18]. During storage in pools or under geological conditions, these cracks could be filled by water. In this work, the simplified geometry used for simulations is cracks with plane parallel faces. Figure $1 \mathrm{~b}$ presents a schematic layout of an ideal crack as simulated here by 2 cylindrical $\mathrm{UO}_{2}$ fuel specimens 
( $2 \mathrm{~cm}$ diameter and $1 \mathrm{~mm}$ thick) spaced by the kind of water-filled aperture described above (from $5 \mu \mathrm{m}$ to $35 \mu \mathrm{m}$ aperture values).

\subsection{Physical quantities}

\subsubsection{Theoretical approach}

The dose rate in a thin target through which a beam of charged particles passes is given by the following equation [19-20] :

$$
\dot{D}=\mathrm{K} . \mathrm{F} \cdot\left(-\frac{1}{\rho} \cdot \frac{d E}{d x}\right)
$$

where:

$\dot{D}=$ dose rate $\left[G y \cdot h^{-1}\right]$

$\mathrm{K}=\mathrm{a}$ constant $=1.7310^{12}\left[\mathrm{~J} \cdot \mathrm{g} \cdot \mathrm{s} \cdot \mathrm{eV}^{-1} \cdot \mathrm{kg}^{-1} \cdot \mathrm{h}^{-1}\right]$

$F=$ flux of particles $\left[\right.$ particles. $\left.\mathrm{cm}^{-2} \cdot \mathrm{s}^{-1}\right]$

$\frac{d E}{d x}=$ linear energy transfer (LET) $\left[\mathrm{MeV} . \mathrm{cm}^{-1}\right]$

$\rho=$ mass density of the material $\left[\mathrm{g} \cdot \mathrm{cm}^{-3}\right]$

Passing from the $\mathrm{UO}_{2}$ fuel to the water, the flux of alpha particles $\mathrm{F}$ must be continuous at the interface. The boundary condition is therefore that the flux of particles leaving the $\mathrm{UO}_{2}$ fuel equals the flux into water [19]. At the interface, the alpha dose rate in a water layer in 
contact with the $\mathrm{UO}_{2}$ fuel surface is thus related to the dose rate in the outer $\mathrm{UO}_{2}$ fuel layer, according to the following equation:

$$
Q_{i}=\frac{\dot{D}\left(\mathrm{H}_{2} O\right)}{\dot{D}\left(\mathrm{UO}_{2}\right)}=\frac{\left[\frac{1}{\rho} \cdot \frac{d E}{d x}\right]_{\mathrm{H}_{2} O}}{\left[\frac{1}{\rho} \cdot \frac{d E}{d x}\right]_{\mathrm{UO}_{2}}}
$$

\subsubsection{Output data given by simulation}

In this study, the focus was on dose rate values. The dose rate was calculated from the deposited energy value $E d_{0}$ by using Equation 3. It must be specified here that $E d_{0}$ is an average value given in a volume (and expressed per mass unit), obtained by using the output data called "Tally 6" in the MCNPX code. As the deposited energy values for alpha particles can vary widely over just a couple of microns, it is thus necessary to consider very small homogeneous volumes in which an average value would be a good approximation of the actual value of the dose rate at a given distance.

$$
\dot{D}=E d_{0} \times A \times C
$$

where:

$\dot{D}=$ dose rate $\left[\mathrm{Gy} \cdot \mathrm{h}^{-1}\right]$

$E d_{0}=$ average deposited energy density per source particle [MeV.g $\mathrm{g}^{-1}$.source particle $\left.{ }^{-1}\right]$

$A=$ activity of the system $\left[\mathrm{Bq}=\right.$ source particle. $\left.\mathrm{s}^{-1}\right]$

$C=$ Conversion factor $=5.7610^{-7}\left[\mathrm{~s} \cdot \mathrm{h}^{-1} \cdot \mathrm{J} \cdot \mathrm{MeV}^{-1} \cdot \mathrm{g} \cdot \mathrm{kg}^{-1}\right]$

Each output value calculated by MCNPX simulation is given with its corresponding statistical error. 


\section{Results and discussion}

\subsection{Influence of the thickness of the layers investigated and of the}

geometry

Figure 2 shows the evolution of the dose rate in $\mathrm{UO}_{2}$ and in water depending on the thickness of the layers examined at the reactional interface. It should be noted that for the spherical geometry under consideration (100 $\mu \mathrm{m}$ diameter) and a statistically large population (500 000 particles), the profiles obtained were not significantly modified by the step size, which varied between $0.0625 \mu \mathrm{m}$ and $1 \mu \mathrm{m}$.

Concerning the overall appearance of the profiles, it seems that the energy deposition in the water has an exponentially declining rate, with a maximum dose rate value at the extreme surface and a rapid decrease within the first $30 \mu \mathrm{m}$. This is in agreement with the results previously described in the literature, where other means of analytical calculation were used. The energy deposited at $40 \mu \mathrm{m}$, which corresponds to the average path of $5.3 \mathrm{MeV}$ alpha particles in water, is very weak as only the alpha particles emitted at the extreme surface of the fuel and perpendicular to the interface contribute to this distance. For dose rate values in the $\mathrm{UO}_{2}$, an inverse exponential profile was obtained at the surface, and the energy deposited is less than that in the bulk. This is due to the alpha particle energy coming from the solid being dissipated in the water. The profile extends over about $10 \mu \mathrm{m}$ as only the 5.3 $\mathrm{MeV}$ alpha particles emitted less than $12.6 \mu \mathrm{m}$ from the surface are likely to emerge from $\mathrm{UO}_{2}$, which is denser than water.

Figure 2 shows a discontinuity at the reactional interface between the dose rates in water and in $\mathrm{UO}_{2}$. From a physical point of view, there is obviously a particle flux continuity at the reactional interface [19], as describe in a similar study on glasses [21]. This discontinuity 
comes thus from Equation 2 which links the ratio of dose rates to the densities of the encountered media and their corresponding LET values.

In order to evaluate the ratio of theoretical dose rates expected at the reactional interface, it is necessary to know the average energy of the alpha particles at the interface. It can be estimated using the following relationship [22] (Equation 4)

$E_{\text {average }}=\frac{A}{2 L}\left(\frac{2 E_{0}^{3}}{3}+\frac{B}{A} E_{0}^{2}\right)$

Equation 4

Here, the average energy was $2.62 \mathrm{MeV}$. The dose rate ratio calculation at the reactional interface must thus take the LET values associated with this $2.62 \mathrm{MeV}$ average energy into account. They were respectively $140 \mathrm{keV} / \mu \mathrm{m}$ and $425 \mathrm{keV} / \mu \mathrm{m}$ in the water and in the $\mathrm{UO}_{2}$, on the basis of a SRIM calculation [17]. Considering the water and $\mathrm{UO}_{2}$ media densities, Equation 2 led to a theoretical dose rate ratio of 3.56 at the reactional interface. This value can be compared to those obtained by MCNPX simulations, grouped in Table 2 depending on the thickness of the layers examined near the interface. It is worth noting that the smaller the step, the closer the dose rate ratio is to the expected theoretical value. This means that small layer thicknesses should be focused on in order to correctly appreciate the energy transfers at the interface.

Figure 3 illustrates the dependence of the energy deposit profiles calculated with the geometry under consideration (spheres with different diameters, or pellet). Whatever the geometry involved, the profiles remain similar. Nevertheless they overlap perfectly in water for diameters greater than or equal to $500 \mu \mathrm{m}$, indicating behavior equivalent to that of an infinite planar geometry as is the case for pellets. Concerning the solid, the profiles overlap 
including for the $100 \mu \mathrm{m}$ diameter, as in this case it is larger than alpha particle paths in the solid.

On the basis of these calculations, the same general equations to those proposed by S.

Mougnaud et al. [21] can be adapted to the present system and can be written as followed:

$$
\begin{aligned}
& \dot{D}_{U O 2}=\dot{D}_{U O 2 \text { bulk }}-\left(\frac{\dot{D}_{U O 2 \text { bulk }}}{2}\right) \times \exp \left(\frac{\text { distance }}{R p_{U O 2} / 4}\right) \\
& \dot{D}_{\text {water }}=\left(\frac{\dot{D}_{U O 2 \text { bulk }} \times Q_{i}}{2}\right) \times \exp \left(\frac{- \text { distance }}{R p_{U O 2} / 4}\right) \\
& \text { With } \dot{D}_{U O 2 \text { bulk }}=1445 \mathrm{~Gy} / \mathrm{h} \\
& Q_{i}=3.56 \\
& R_{\text {pUO2 }}=12.6 \mu \mathrm{m} \\
& R_{\text {pwater }}=40 \mu \mathrm{m}
\end{aligned}
$$

\subsection{Comparison with profiles from the literature}

First, to the authors' knowledge, no study in the literature proposes a description of the radiation field decay at the interface in the emitter material side (except the one of Mougnaud et al. [21] performed on glass by using the same MCNPX approach). It is however interesting to describe the last few micrometers of the material for the study of thin layers forming at the interface, especially when focusing on alteration mechanisms.

The results presented here, obtained from MCNPX calculations, can thus only be compared and discussed taking into account previous studies focusing on radiation fields in water for 
spent fuel matrixes. Results on dose rate profiles in water can be compared to the works of Nielsen [13] and Poulesquen [12] on fuel pellets in contact with water and on the corresponding alpha decay profile in water. As the characteristics of the spent fuel studied in the work of Nielsen [13] are very different, the fraction of maximal dose rate versus distance from interface has been plotted in order to be able to compare the resulting profiles. Results are presented in Figure 4 (a). It can first be noted that in the three approaches, dose rate profiles decrease rapidly with distance from the interface. However, even if the general shape of these three curves are quite similar (i.e. a global strong decrease of the dose rate values with the distance), the precise dose rate values at a given distance remain very different from one study to another. Our results are in good agreement with those of Nielsen, although the alpha dose rate in the first $2 \mu \mathrm{m}$ are lacking in Nielsen's description. In fact, taking these values into account to calculate the fraction of maximal dose rate would significantly change the shape of the curve for the first micrometers, as the dose rate close to the interface is high and decreases rapidly. The resulting renormalized dose rate profile from Nielsen's results would thus be a little lower than that presented in Figure 4 (a) if data in the two first micrometers had been taken into account. But, the dose rate profile described by Poulesquen remains very different from the 2 others. In that case, as the spent fuel characteristics are similar in the work of Poulesquen and in ours (UOx spent fuel with an alpha activity of $\left.4.73 \times 10^{8} \mathrm{~Bq} \cdot \mathrm{g}_{\mathrm{HM}}{ }^{-1}\right)$, dose rate profiles can also be plotted to compare these two approaches and they are presented in Figure 4 (b). In the model developed by Poulesquen, the dose rate values are much higher than the values obtained in the present work very close to the interface and the decrease observed is very sharp resulting in lower dose rate values farer from the interface: most alpha particles stop in the first $5 \mu \mathrm{m}$, which means they arrive at the material/water interface with a significantly lower energy than that found in our study. The Bragg peak is then shifted towards the smaller distances to the interface, and alpha particles deposit their energy closer to it. This difference may be due to the relative importance given to alpha with low energies in the calculative approach developed by Poulesquen (a $5 \mu \mathrm{m}$ alpha particle range in water would correspond to $1 \mathrm{MeV}$ 
alpha particles, from SRIM simulation) which passed through a thicker layer of material before reaching the surface and then the water. Furthermore, it can be noticed that the average dose rate values are similar in Poulesquen's study [12] (1029 Gy/h) and in the present work (1076 $\pm 23 \mathrm{~Gy} / \mathrm{h})$ which means that the same global energy is deposited into water and it is in agreement with the fact that we consider the same alpha activity in these two studies.

In conclusion, the two studies which propose in the literature a profile description of the dose rate evolution are both based on mathematical models developed by the authors. In the present study, the profiles are calculated by using an existing Monte-Carlo based code. In order to check and to approve the robustness of this method, a sensitivity study has been performed and presented in the previous paragraph (geometry of the fuel, accuracy of the interface description, source particle number up to 2 millions). We are thus confident on the reliability of the use of the MCNPX code to model this kind of system as it has the advantage of giving a very precise description of the interface (including the first micrometers on either side of the interface) and of taking into account all particle energies equally.

\subsection{Dose rates in the cracks}

Figure 5 shows the dose rate evolution for different sized cracks. When the crack is between 5 and 20 microns wide, it seems that the dose rate profiles in water are added from the two opposite surfaces. For the smaller sizes (5 $\mu \mathrm{m}$ - Figure 5-a), the energy deposition in the water is fairly regular and increases by a factor of approximately 1.8 compared to a single surface (3750 Gy/h in the crack, versus $2300 \mathrm{~Gy} / \mathrm{h}$ for a single surface) at the interface. The energy deposition is high, because it corresponds to the sum of two symmetrical contributions at the exponential function maximum. Once a crack aperture is larger than 20 $\mu \mathrm{m}$ (Figure 5-c), the dose rate in the water remains higher than that of a single surface while 
showing a definite minimum at the mid-crack point. For a $35 \mu \mathrm{m}$ crack (Figure 5-d), the minimum energy deposition in water corresponds to the dose rate value in the $\mathrm{UO}_{2}$ solid. The two surfaces can be considered as being independent for crack aperture widths greater than or equal to $60 \mu \mathrm{m}$ and alpha particles of $5.3 \mathrm{MeV}$ [21].

It is also interesting to note that the energy deposits in the solid show decreasing profiles which are less significant for the small-sized cracks (5 and $10 \mu \mathrm{m}$ ). Under these conditions, the alpha particles emitted by a surface pass through the crack fissure and re-deposit in significant amounts on the other side in the $\mathrm{UO}_{2}$. The wider the crack, the lower this phenomenon, and the dose rate profile decrease in the $\mathrm{UO}_{2}$ solid then becomes significant again, as in the case of a single surface, from a crack of over $20 \mu \mathrm{m}$ aperture.

\subsection{Influence of the water at the interface on the chemistry}

It is interesting to study these calculations bearing in mind considerations as to the local chemistry of the water and to the average free path of the radicals and stable molecular species generated by water radiolysis.

Just considering a very simple system (pure water, absence of radical scavengers, no consideration of the interface), the mean range of radicals depends on the local dose rate [23]. Thus, calculating the mean range of the $\mathrm{OH}^{\circ}$ radicals produced under alpha radiolysis from the method proposed by $\mathrm{H}$. Christensen et al. [23] led to a value of $16 \mu \mathrm{m}$ for a dose rate of $3750 \mathrm{~Gy} / \mathrm{h}$ (dose rate value calculated in a $5 \mu \mathrm{m}$ crack). This means that the $\mathrm{OH}^{\circ}$ radicals generated by alpha radiolysis are able to interact with the two opposite surfaces within this crack. However, in the case of a wider crack $(35 \mu \mathrm{m})$ the dose rate evolution in the crack is more marked, as it varies from 2500 to $1250 \mathrm{~Gy} / \mathrm{h}$ between the $\mathrm{UO}_{2}$ surface and the center of the crack. This dose rate is also weaker than in a small crack, leading to higher mean range value (18 to $21 \mu \mathrm{m}$ ). This $35 \mu \mathrm{m}$ rack width corresponds to a limit beyond which 
the $\mathrm{OH}^{\circ}$ radicals generated can potentially no longer interact with the two opposite surfaces, as their mean range is slightly greater than half the crack width. Concerning the stable molecular species like $\mathrm{H}_{2} \mathrm{O}_{2}$, whose average free path is around a hundred microns [23], they can interact with the two opposite surfaces more easily however wide the crack may be. This paragraph remains a very simple approach that illustrate the interest of a good knowledge of interfacial dose rate evolutions. The values of the radical ranges would clearly depend on the chemistry of the system and must be adapted when more complex chemical environments are considered $[5,11]$.

Crack thickness will also be an essential parameter for the phenomenon of clogging by secondary phase precipitations. Recent work [8] has highlighted the large amount of iron hydroxide precipitation (akaganeite) on the surface of $\mathrm{Pu}$ doped $\mathrm{UO}_{2}$ pellets, and having an alpha activity equivalent to that considered in these calculations. The Fe(II) present in solution via the corrosion of an iron blade oxides into $\mathrm{Fe}(\mathrm{III})$ by reaction with $\mathrm{H}_{2} \mathrm{O}_{2}$ at the very location where this species is produced by water radiolysis. The pellet surfaces are thus completely covered with iron (akaganeite) to a thickness of about $15 \mu \mathrm{m}$, i.e. in the zone where the alpha energy deposition is the highest. It is clear that in the case of $5 \mu \mathrm{m}$ cracks, a fast and complete clogging can be expected for the crack. This will not necessarily be the case for wider cracks, unless it happens over longer periods of time. 


\section{Conclusion}

This work, which contributes to better understanding the nature and evolution of energy deposited at the $\mathrm{UO}_{2} /$ water reactional interface subjected to alpha irradiation, represents an original approach based on Monte Carlo-type simulations using the MCNP® code. This method has the advantage of describing the energy deposition profiles for both sides of the interface, i.e. within the $\mathrm{UO}_{2}$ solid and in the water, and thus adds to and completes the simulations already found in the literature.

The strong discontinuity observed for the dose rate evolutions between the solid and the solution comes from the values of the densities and of the energy transfers, which are significantly different between the two media (water and $\mathrm{UO}_{2}$ ). Furthermore, the choice of step distance (thickness of the layers examined close to the interface) is also an essential point in describing the interface, as the smaller the step, the closer the dose rate ratios at the reactional interface are to the expected theoretical value.

The calculations used here have also enabled evolution laws to be proposed for the dose rates, based on exponential functions which can be directly used by researchers seeking a better understanding of the reactional interface studied.

From the point of view of the contribution of such calculations to the description of real systems (for example, the case of a cracked irradiated fuel), the situation for cracks with various aperture sizes was also examined. For cracks smaller than $60 \mu \mathrm{m}$, the energy deposits are summed to become significantly higher than is the case for a single surface (factor of 1.8 for a $5 \mu \mathrm{m}$ crack) and the profile in the crack, which curves through a minimum, depends on the aperture width. For cracks smaller than $10 \mu \mathrm{m}$, the minimum is only slightly marked as the alpha particles emitted by a surface pass through the crack and are re- 
deposited on the other side in the solid. From $20 \mu \mathrm{m}$ upward, the minimum is more noticeable and becomes equal to the dose rate in $\mathrm{UO}_{2}$ from $35 \mu \mathrm{m}$.

The calculations have also enabled new information on the mean range of radiolytic species in cracks, and thus on the local chemistry. For example in pure water, beyond $35 \mu \mathrm{m}$ and for the alpha activity under consideration, the $\mathrm{OH}^{\circ}$ radicals generated at a surface can no longer react with the opposite surface of the crack. Crack clogging by the precipitation of secondary phases in a complex system including iron via the consumption of radiolytical species will also depend on the crack width.

To conclude, these calculations represent a contribution which can be integrated in a wider modeling approach, coupling chemistry with transport for example, or more simply as a tool to better understand experimental data and observations. 


\section{References}

[1] C. Cachoir; K. Lemmens, Static dissolution of alpha-doped UO2 in boom clay conditions: Preliminary results. In Scientific Basis for Nuclear Waste Management Xxvii, Oversby, V. M.; Werme, L. O., Eds. Materials Research Society: Warrendale, 2004; Vol. 807, pp 59-64.

[2] C. Cachoir; P. Carbol; J. Cobos-Sabate; J. P. Glatz; B. Grambow; K. Lemmens; A. Martinez-Esparza; T. Mennecart; C. Ronchi; V. V. Rondinella; D. Serrano-Purroy; K. Spahiu; D. H. Wegen; T. Wiss Effect of alpha irradiation field on long-term corrosion rates of spent fuel; JRC-ITU-SCA-2005/01; European Commission Project Spent fuel stability under repository conditions: SFS Work package WP3 Deliverable D9: 2005, 2005; [3] B. Muzeau; C. Jégou; F. Delaunay; V. Broudic; A. Brevet; H. Catalette; E. Simoni; C. Corbel, Journal of Alloys and Compounds 467 (1-2) (2009) 578589.

[4] K. Ollila; V. Oversby, Testing of uranium dioxide enriched with U-233 under reducing conditions. In Scientific Basis for Nuclear Waste Management XXIX, VanIseghem, P., Ed. Materials Research Society: Warrendale, 2006; Vol. 932, pp 441-448.

[5] T. E. Eriksen; D. W. Shoesmith; M. Jonsson, J. Nucl. Mater. 420 (1-3) (2012) 409-423.

[6] V. V. Rondinella; H. Matzke; J. Cobos; T. Wiss, Radiochim. Acta 88 (9-11) (2000) 527-531.

[7] S. Stroes-Gascoyne; F. Garisto; J. S. Betteridge, J. Nucl. Mater. 346 (1) (2005) 5-15.

[8] M. Odorowski. Etude de l'altération de la matrice (U,Pu)O2 du combustible irradié en conditions de stockage géologique : approche expérimentale et modélisation géochimique. Ecole Nationale Supérieure des Mines de Paris, 2015.

[9] K. Ollila; E. Myllykyla; M. Tanhua-Tyrkko; T. Lavonen, J. Nucl. Mater. 442 (1-3) (2013) 320-325.

[10] M. Amme; R. Pehrman; R. Deutsch; O. Roth; M. Jonsson, J. Nucl. Mater. 430 (1-3) (2012) 1-5.

[11] P. Carbol; P. Fors; T. Gouder; K. Spahiu, Geochimica et Cosmochimica Acta 73 (15) (2009) 4366-4375.

[12] A. Poulesquen; C. Jegou; S. Peuget, Scientific Basis for Nuclear Waste Management XXIX 932 (2006) 505-512.

[13] F. Nielsen; M. Jonsson, J. Nucl. Mater. 359 (1-2) (2006) 1-7.

[14] L. S. Waters; G. W. McKinney; J. W. Durkee; M. L. Fensin; J. S. Hendricks; M. R. James; R. C. Johns; D. B. Pelowitz, The MCNPX Monte Carlo radiation 
transport code. In Hadronic Shower Simulation Workshop, Albrow, M.; Raja, R., Eds. Amer Inst Physics: Melville, 2007; Vol. 896, pp 81-90. [15] X-5_Monte-Carlo_Team MCNP - A General N-Particle Transport Code, Version 5, 2003.

[16] F. B. Brown, Fundamentals of Monte Carlo Particle Transport, LA-UR05-4983. Los Alamos National Laboratory: 2005.

[17] J. F. Ziegler; J. P. Biersack; M. D. Ziegler, SRIM, the stopping and range of ions in matter. SRIM Co.: Chester, Maryland, 2008.

[18] L. Barbié. Raffinement de maillage multi-grille local en vue de la simulation 3D du combustible nucléaire des Réacteurs à Eau sous Pression. Université d'Aix -Marseille, 2013.

[19] S. Sunder, Nucl. Technol. 122 (2) (1998) 211-221.

[20] W. T. Spinks; R. J. Woods, An Introduction to Radiation Chemistry. 3rd ed.; Wiley Interscience: New York, 1990; p 592.

[21] S. Mougnaud; M. Tribet; S. Rolland; J. P. Renault; C. Jégou, J. Nucl. Mater. 462 (2015) 258-267.

[22] F. Garisto, Ann. Nucl. Energy 16 (1) (1989) 33-38.

[23] S. S. Hilbert Christensen, J. Nucl. Mater. 238 (1996) 70-77. 


\section{Table and figure captions}

Table 1: Details of the parameters taken into account in the MNCP calculations.

Table 2: Dose rate values and associated uncertainties (given by MCNPX) at the water/UO interface on the $\mathrm{UO}_{2}$ side and the water side for a $100 \mu \mathrm{m}$ diameter sphere and for different refinement steps. Calculation of dose rate ratio at the interface for each step.

Table 3: Dose rates values and associated uncertainties (given by MCNPX) at the water/UO interface on the $\mathrm{UO}_{2}$ side and the water side for a $2 \mathrm{~cm}$ diameter pellet, considering different refinement steps. Calculation of dose rate ratio at the interface for each step.

Figure 1: Schematic view of the simulated geometries. (a) Spherical geometry with a $\mathrm{UO}_{2}$ sphere surrounded by water. (b) Cylindrical geometry with $\mathrm{UO}_{2}$ pellet(s) in water. In the latter case, the ideal crack filled by water is simulated by the water contained between two $\mathrm{UO}_{2}$ pellets.

Figure 2: Comparison of dose rate profiles for $1 \mu \mathrm{m}, 0.125 \mu \mathrm{m}$ and $0.0625 \mu \mathrm{m}$ refinement steps at the $\mathrm{UO}_{2} /$ water interface for a $100 \mu \mathrm{m}$ diameter $\mathrm{UO}_{2}$ sphere.

Figure 3: Dose rates at the $\mathrm{UO}_{2} /$ water interface for the different geometries detailed in Table 1, i.e. $100 \mu \mathrm{m}, 500 \mu \mathrm{m}$ and $1 \mathrm{~mm}$ diameter spheres (refinement step $=1 \mu \mathrm{m}$ ), and also $8 \mathrm{~mm}$ and $2 \mathrm{~cm}$ diameter pellets (refinement step $=0.0625 \mu \mathrm{m}$ ). Resulting fitted curves obtained for dose rate profiles in $\mathrm{UO}_{2}$ and in water are shown in red.

Figure 4: Comparison of alpha dose rate profiles with literature data [12-13] (a) after normalization to 1 of the water dose rate at the interface (b) directly as the fuel characteristics are the same between [12] and the present work.

Figure 5: Dose rate profiles in cracks with different aperture values: (a) $5 \mu \mathrm{m}$, (b) $10 \mu \mathrm{m}$, (c) $20 \mu \mathrm{m}$ and (d) $35 \mu \mathrm{m}$. In each calculation, 2.5 million source particles were considered in order to be accurate. 
Table 1

\begin{tabular}{|c|c|c|c|}
\hline geometry & diameter & interface refinement steps & source particle number (NPS) \\
\hline \multirow{8}{*}{ sphere } & \multirow{3}{*}{$100 \mu \mathrm{m}$} & $1 \mu \mathrm{m}$ & \multirow{8}{*}{500000} \\
\hline & & $0.125 \mu \mathrm{m}$ & \\
\hline & & $0.0625 \mu \mathrm{m}$ & \\
\hline & \multirow{2}{*}{$500 \mu \mathrm{m}$} & $1 \mu \mathrm{m}$ & \\
\hline & & $0.0625 \mu \mathrm{m}$ & \\
\hline & \multirow{3}{*}{$1 \mathrm{~mm}$} & $1 \mu \mathrm{m}$ & \\
\hline & & $0.125 \mu \mathrm{m}$ & \\
\hline & & $0.0625 \mu \mathrm{m}$ & \\
\hline \multirow{5}{*}{$\begin{array}{c}1 \mathrm{~mm} \text { thick } \\
\text { pellet }\end{array}$} & \multirow{2}{*}{$8 \mathrm{~mm}$} & $1 \mu \mathrm{m}$ & 2000000 and 2500000 \\
\hline & & $0.0625 \mu \mathrm{m}$ & 2000000 \\
\hline & \multirow{3}{*}{$2 \mathrm{~cm}$} & $0.25 \mu \mathrm{m}$ & 2000000 \\
\hline & & $0.125 \mu \mathrm{m}$ & 2000000 \\
\hline & & $0.0625 \mu \mathrm{m}$ & 2000000 \\
\hline
\end{tabular}


Table 2

\begin{tabular}{|c|c|c|c|c|c|c|}
\cline { 2 - 7 } $100 \mu$ m diameter sphere & \multicolumn{2}{|c|}{ dose rate in $\mathrm{UO}_{2}(\mathrm{~Gy} / \mathrm{h})$} & \multicolumn{2}{c|}{ dose rate in water $(\mathrm{Gy} / \mathrm{h})$} & \multicolumn{2}{c|}{ dose rate ratio } \\
\cline { 2 - 7 } & value & uncertainty & value & uncertainty & min & $\max$ \\
\hline $1 \mu \mathrm{m}$ step & 779.4 & 3.0 & 1955.9 & 7.4 & 2.49 & 2.53 \\
\hline $0.125 \mu \mathrm{m}$ step & 680.9 & 3.1 & 2134.3 & 9.0 & 3.11 & 3.16 \\
\hline $0.0625 \mu \mathrm{m}$ step & 670.8 & 3.2 & 2153.4 & 9.3 & 3.18 & 3.24 \\
\hline
\end{tabular}


Table 3

\begin{tabular}{|c|c|c|c|c|c|c|}
\hline \multirow{2}{*}{$2 \mathrm{~cm}$ diameter pellet } & \multicolumn{2}{|c|}{ dose rate in $\mathrm{UO}_{2}(\mathrm{~Gy} / \mathrm{h})$} & \multicolumn{2}{c|}{ dose rate in water $(\mathrm{Gy} / \mathrm{h})$} & \multicolumn{2}{c|}{ dose rate ratio } \\
\cline { 2 - 7 } & value & uncertainty & value & uncertainty & min & $\max$ \\
\hline $0.250 \mu \mathrm{m}$ step & 757.0 & 14.8 & 2251.5 & 41.9 & 2.86 & 3.09 \\
\hline $0.125 \mu \mathrm{m}$ step & 717.7 & 14.4 & 2241.4 & 41.5 & 3.00 & 3.25 \\
\hline $0.0625 \mu \mathrm{m}$ step & 701.2 & 14.2 & 2306.9 & 45.7 & 3.16 & 3.42 \\
\hline
\end{tabular}


Figure 1

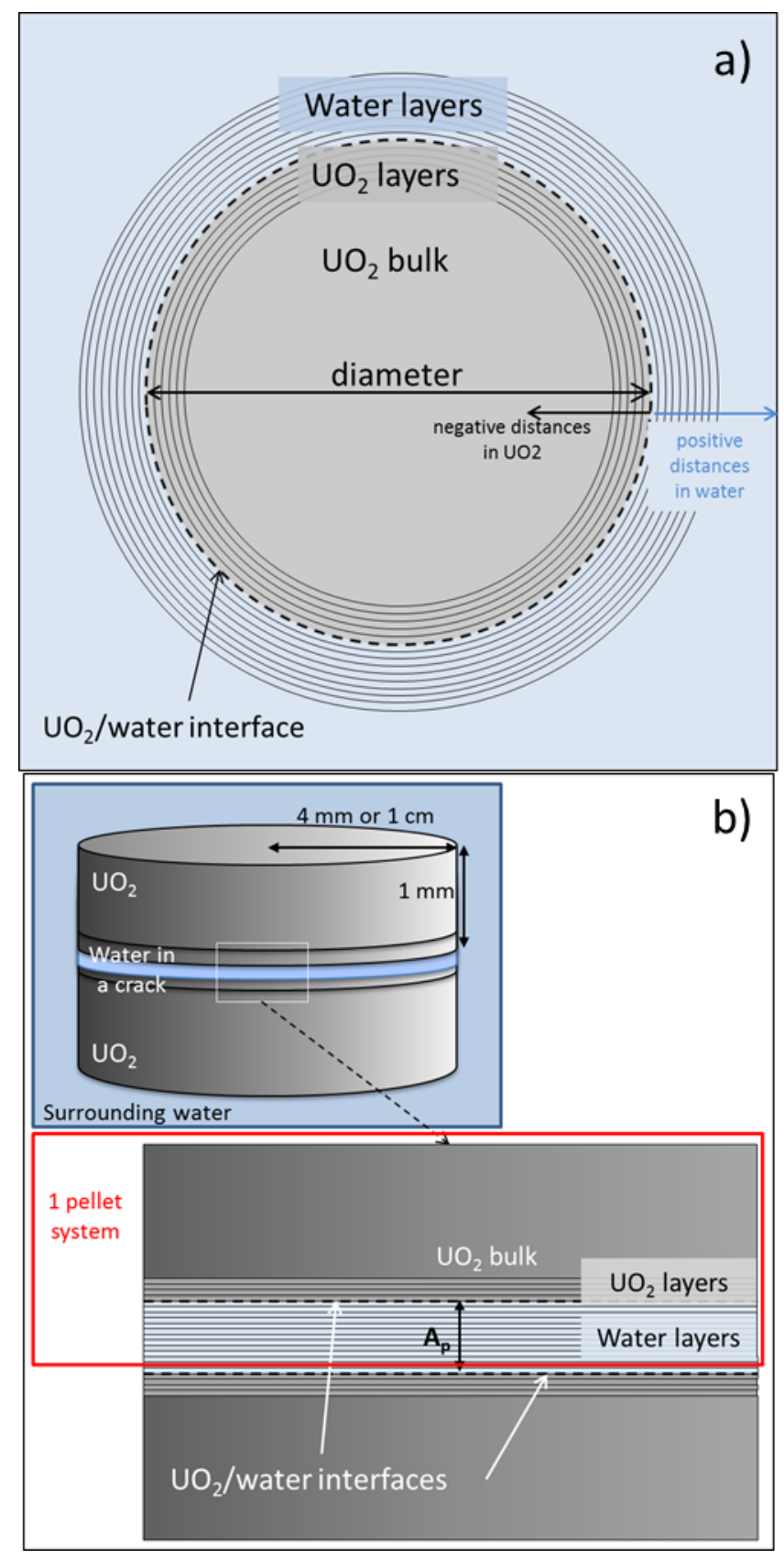


Figure 2

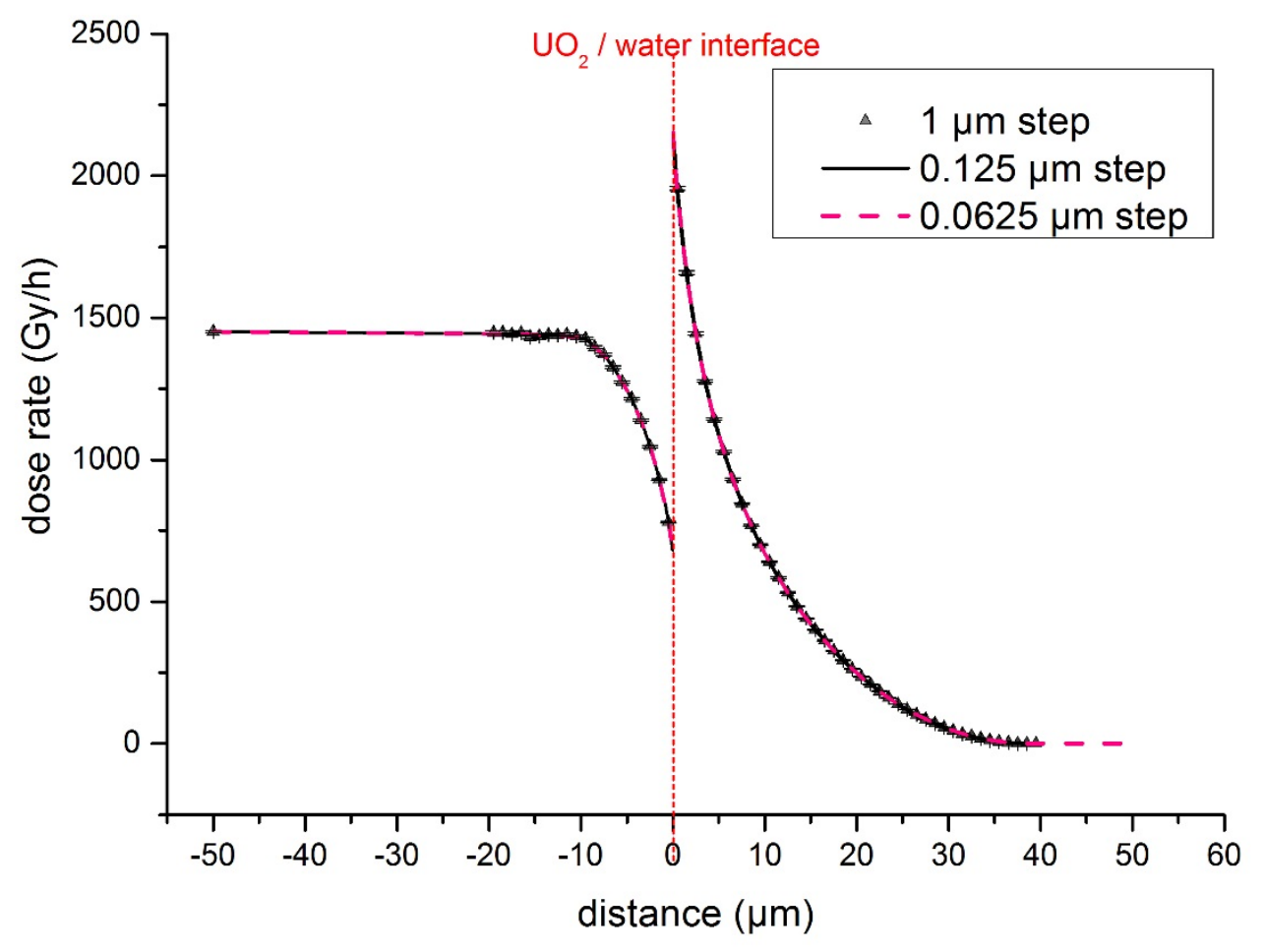


Figure 3

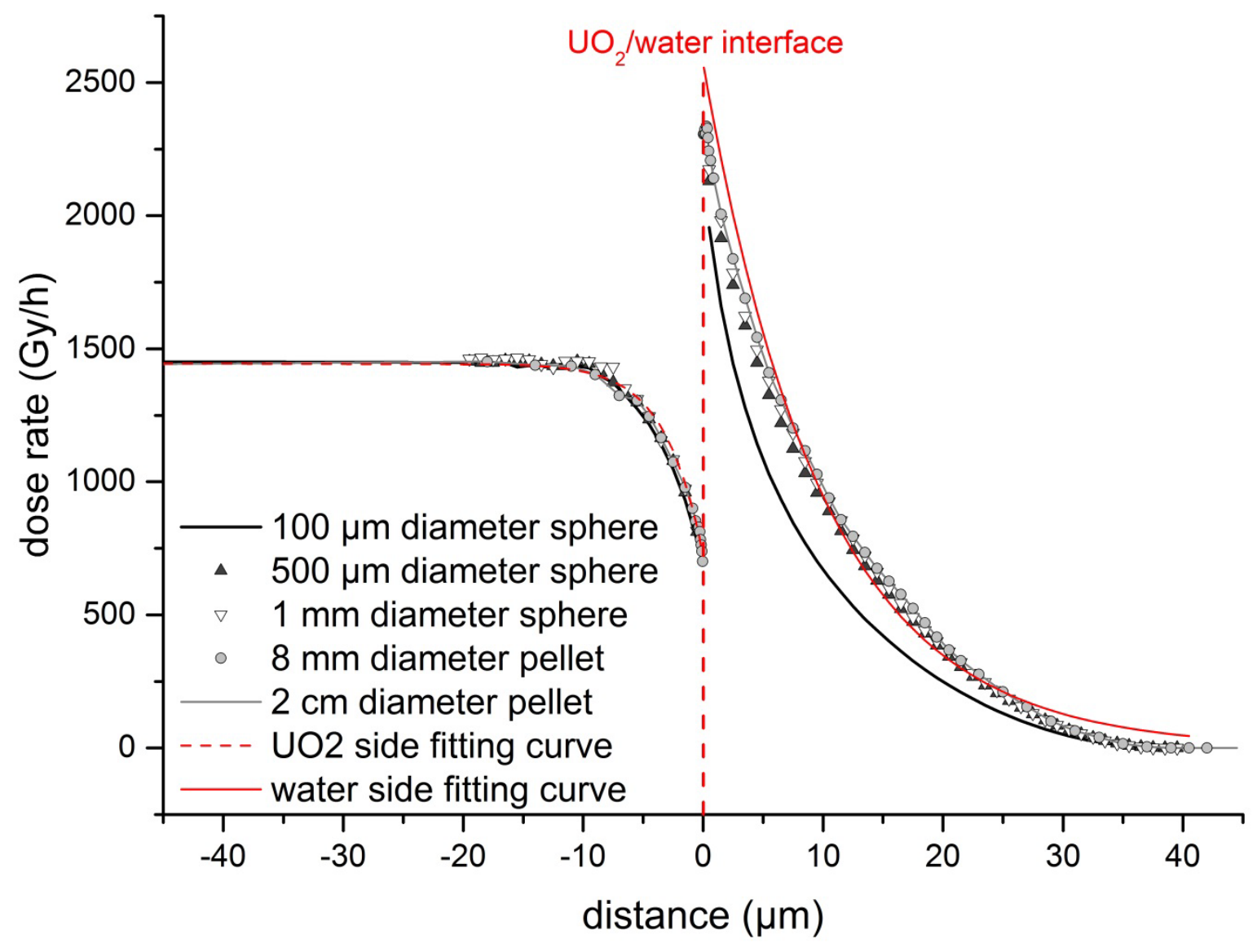




\section{Figure 4}
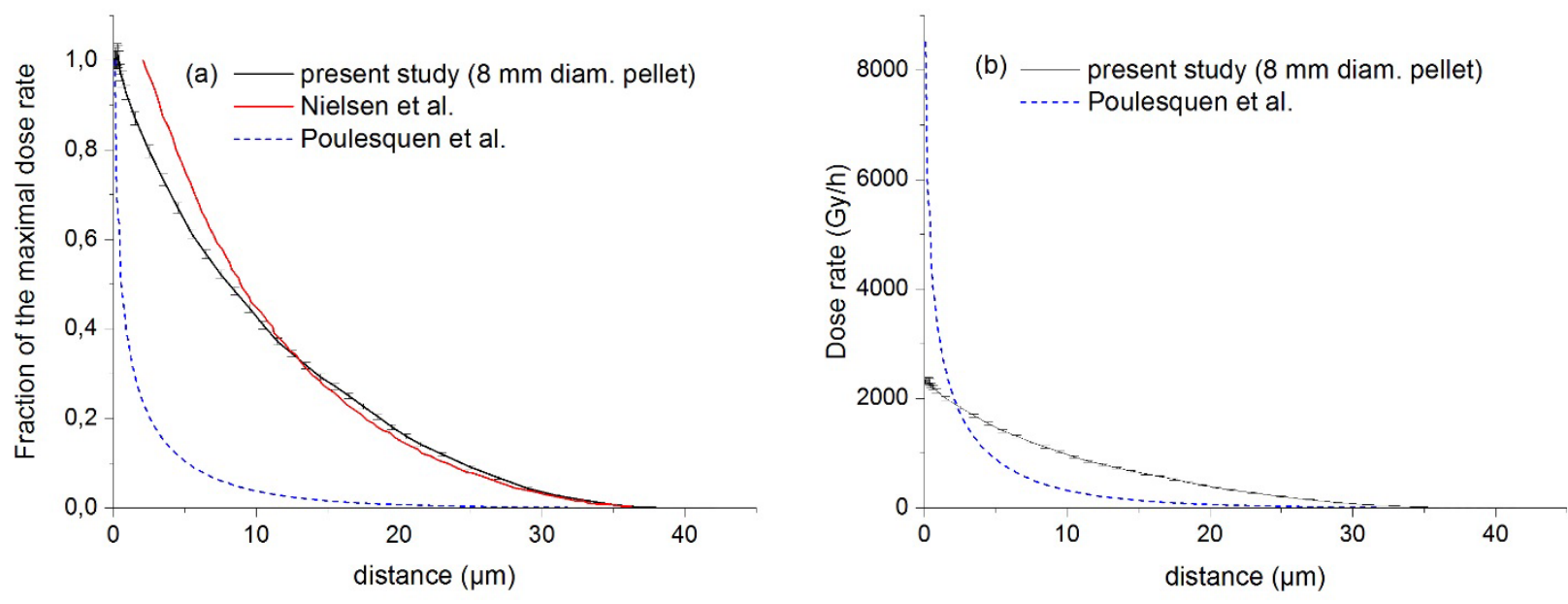


\section{Figure 5}

a)
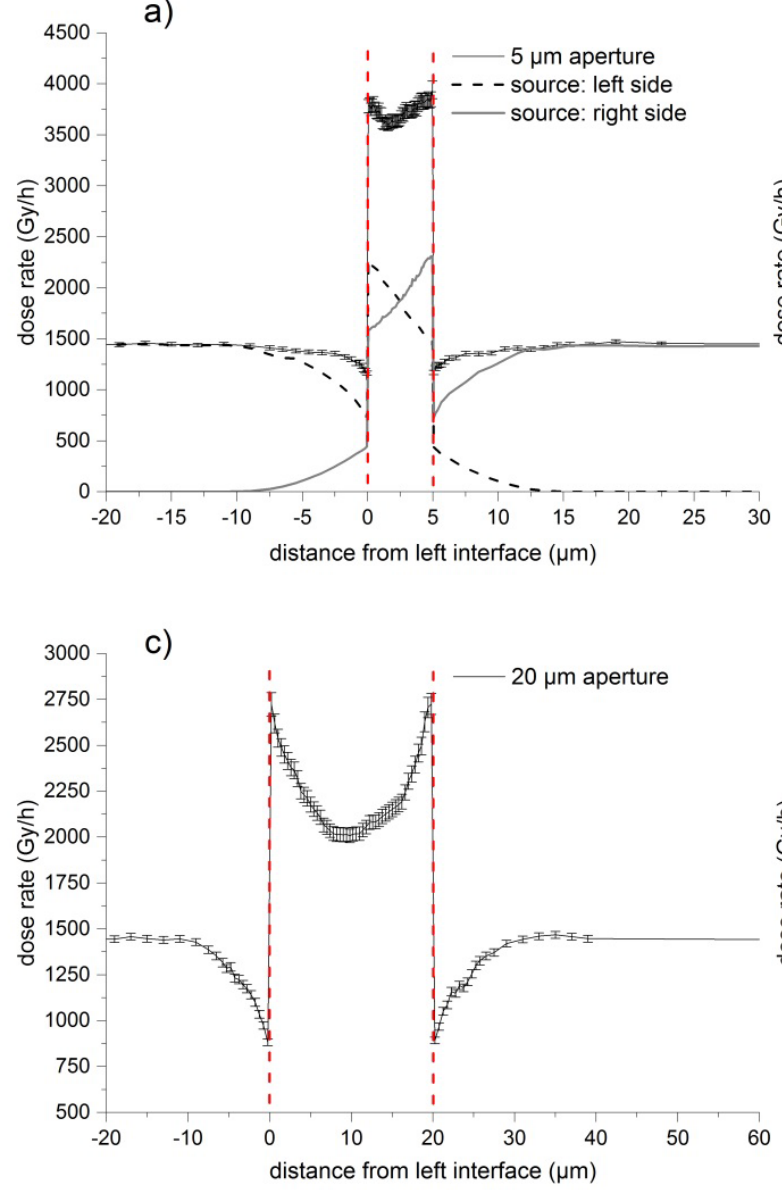

b)

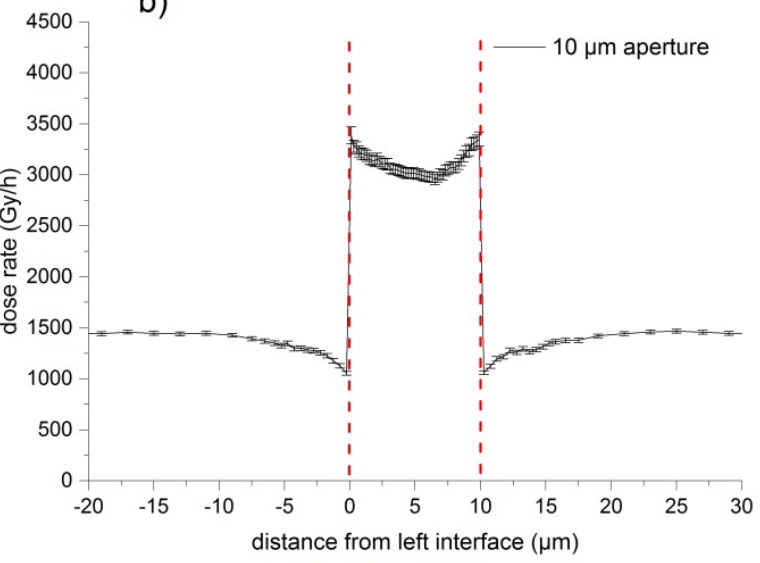

d)

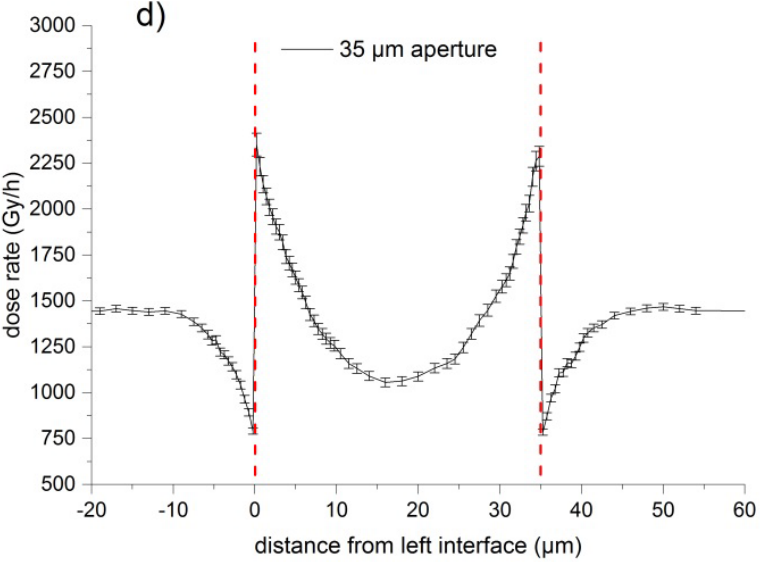

